\title{
Structural and congenital heart disease interventions: the role of three-dimensional printing
}

\author{
L. M. Meier ${ }^{1}$ M. Meineri' ${ }^{2}$ J. Qua Hiansen ${ }^{2}$ E. M. Horlick ${ }^{1}$
}

Published online: 12 January 2017

(C) The Author(s) 2017. This article is available at SpringerLink with Open Access.

\begin{abstract}
Advances in catheter-based interventions in structural and congenital heart disease have mandated an increased demand for three-dimensional (3D) visualisation of complex cardiac anatomy. Despite progress in 3D imaging modalities, the pre- and periprocedural visualisation of spatial anatomy is relegated to two-dimensional flat screen representations. 3D printing is an evolving technology based on the concept of additive manufacturing, where computerised digital surface renders are converted into physical models. Printed models replicate complex structures in tangible forms that cardiovascular physicians and surgeons can use for education, preprocedural planning and device testing. In this review we discuss the different steps of the 3D printing process, which include image acquisition, segmentation, printing methods and materials. We also examine the expanded applications of 3D printing in the catheter-based treatment of adult patients with structural and congenital heart disease while highlighting the current limitations of this technology in terms of segmentation, model accuracy and dynamic capabilities. Furthermore, we provide information on the resources needed to establish a hospital-based 3D printing laboratory.
\end{abstract}

Electronic supplementary material The online version of this article (doi: 10.1007/s12471-016-0942-3) contains supplementary material, which is available to authorized users.

E. M. Horlick

eric.horlick@uhn.ca

1 Toronto Congenital Cardiac Centre for Adults, Toronto General Hospital, Peter Munk Cardiac Centre, University Health Network, University of Toronto, Toronto, Ontario, Canada

2 Department of Anesthesia and Pain Management, Toronto General Hospital, University Health Network, University of Toronto, Toronto, Ontario, Canada
Keywords Cardiology $\cdot$ Structural heart disease $\cdot$ Heart valve diseases $\cdot$ Congenital heart defects $\cdot$ Transcatheter interventions $\cdot$ Three-dimensional printing

\section{Introduction}

Structural heart disease intervention has been a rapidly growing field in interventional cardiology, involving a broadening variety of catheter-based treatment options for acquired and congenital heart defects. Transcatheter interventions have become the standard of care for several structural and functional abnormalities of heart valves, cardiac chambers and proximal vessels [1]. Patients with congenital heart defects and complex previous operations represent a challenge due to a wide variation in morphology and complex cardiac anatomy. Despite currently available three-dimensional (3D) imaging modalities most procedures are still planned using images viewed on twodimensional (2D) screens. The $2 \mathrm{D}$ representation makes it inherently more difficult to fully appreciate the complex 3D relationships of cardiac structures relevant to particular interventions. 3D printing (also referred to as rapid prototyping, stereolithography or additive manufacturing) is a technology which fabricates a physical model from a 3D computerised imaging source file. The first medical application was used to produce surgical implants for oral and maxillofacial surgery [2] and prosthetics for orthopaedic surgery [3]. The ability to generate a tangible 3D model of complex cardiac anatomy has made this a promising tool for education, preprocedural planning, and device testing in structural and congenital heart disease interventions (Fig. 1; [4-6]). However, due to the expertise required to generate $3 \mathrm{D}$ models and the investment of resources involved the establishment of 3D printing labs has mostly been limited to 
Fig. 1 3D printing workflow and applications

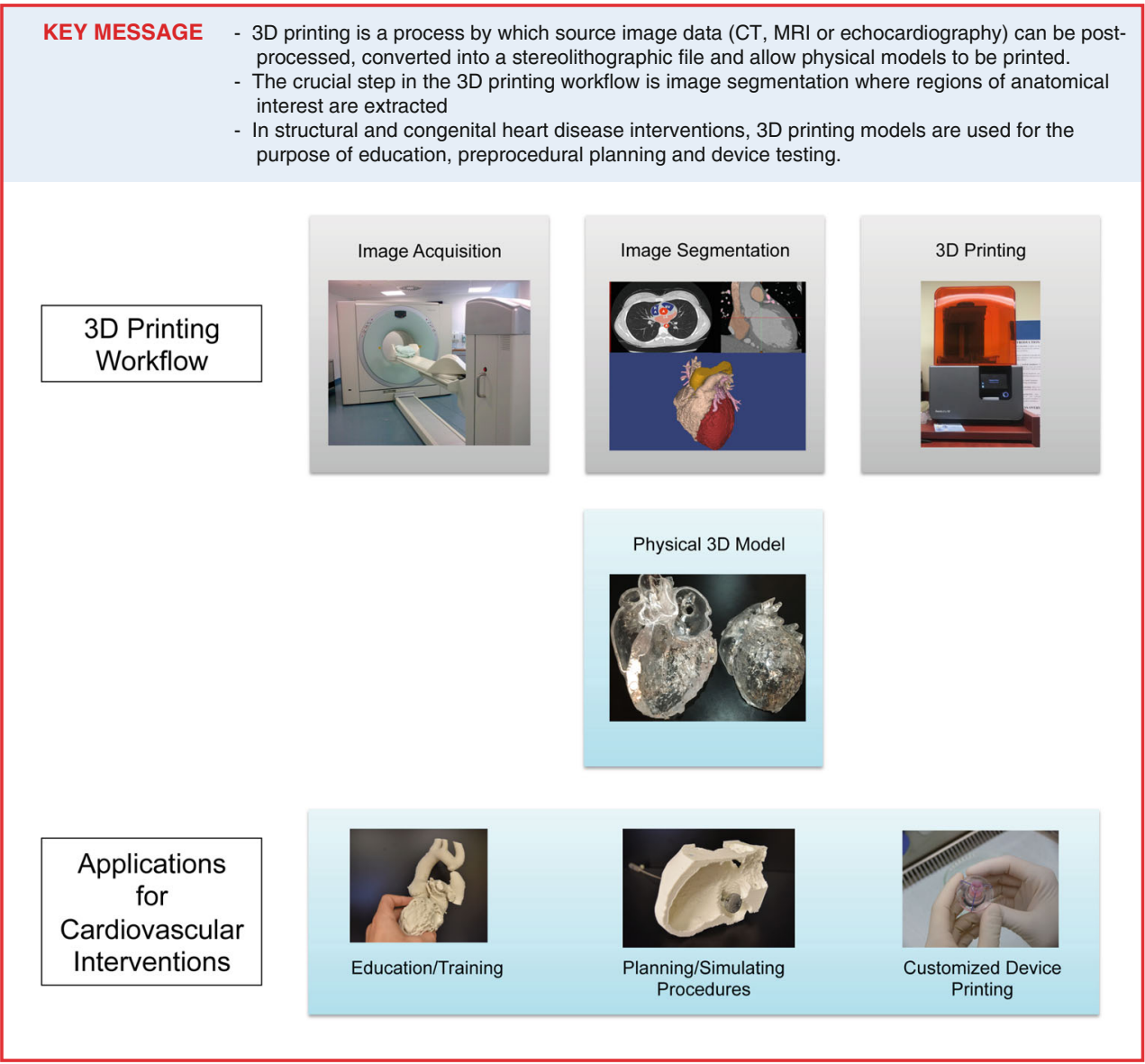

larger teaching hospitals and research centres. This review will discuss a 3D printing workflow, review the expanded applications of 3D printing in the catheter-based treatment of adults with structural and congenital heart disease and will outline the resources needed to establish a hospitalbased $3 \mathrm{D}$ printing laboratory.

\section{D printing step-by-step}

The availability of cross-sectional cardiac imaging, such as magnetic resonance imaging (MRI) or computed tomography (CT), for most patients with complex cardiovascular disease is favourable for the application of 3D reconstruction and printing. 3D echocardiography is also readily available in many clinical settings. Commonly available post-processing software allows anatomic visualisation via $3 \mathrm{D}$ renderings, but these renders cannot be directly printed. Special software is required to process the source imaging datasets to generate a model via segmentation and export it as a stereolithographic (STL) file to be printed (Fig. 1).

\section{Image acquisition}

The three most commonly used medical imaging modalities for 3D image generation are CT, MRI and echocardiography. Spatial resolution, tissue contrast and slice thickness determine the quality of the 3D dataset and are a prerequisite for 3D printing. CT and MRI are the most common sources of datasets for 3D printing because of their ability to image the entire heart with detailed intracardiac anatomy. Echocardiography has a superior ability to image fast moving structures such as cardiac valves [7]. Fusion of different modalities (e.g. ventricles from CT, valves from echocardiography) to create a single 3D model has been reported [8]. Both ECG and non-ECG gated MRI have been used for $3 \mathrm{D}$ modelling and both seem to provide $3 \mathrm{D}$ printed models of comparable quality. Optimal CT images should be contrast enhanced, multiphase ECG-gated acquired during breath-hold [6]. Isotropic volumetric data should be reconstructed with a slice thickness between $0.5-1.25 \mathrm{~mm}$ to ease segmentation and generate accurate $3 \mathrm{D}$ printing models [9]. In echocardiography, conversion to a 'Cartesian' DICOM file is necessary for 3D model generation and this requires special proprietary software (e.g. Philips QLAB, Philips Healthcare, USA). 


\section{Image segmentation}

Segmentation is part of the post-processing sequence wherein source images are partitioned into multiple simple geometrical elements of known coordinates in 3D space. It is achieved using complex techniques such as surface triangulation, isosurfacing and volume rendering.

There is no standardised approach to image segmentation. Several manual, semi-automatic and automatic image segmentation methods have been used. The most common are: region growing and brightness thresholding followed by manual editing [7]. Region growing examines the relationship of neighbouring pixels to an initial seed point and determines whether the neighbouring pixels should be added as part of that region (Fig. 2a, b). Thresholding is a method where pixels are partitioned depending on their intensity or brightness value (Fig. 2c, d). Manual editing is necessary to correct segmentations errors (exclusion of artefacts and/or filling of dropout gaps), surface smoothing, colouring and 3D model cropping. Commercially available software (Mimics, Belgium) combines semi-automatic segmentation and manual editing in a single product and allows segmentation from all imaging modalities. Freeware, such as ITK-SNAP or 3D Slicer [10, 11], is also available but is less user friendly and currently limited to $\mathrm{CT}$ and MRI data. The process is time consuming, requires expertise with specific segmentation software as well as understanding of the patient's complex structural and congenital anatomy. Throughout each step, there is a risk of introducing design errors and manipulating the original source data in order to generate oversimplified 3D models [12].

\section{D printing}

There are three common types of 3D printers used for medical printing. They are as defined by the mechanics and materials used to generate a model: fused deposition modelling (FDM), stereolithography (SLA) and PolyJet 3D printers. These, and other types of 3D printers, are briefly summarised in Table 1.

FDM printers utilise thermo-plastic filaments and a layer-by-layer technique. The filaments are rapidly heated to liquefy the plastic into a semi-molten state and then extruded in a very thin layer onto a heated surface [13]. Once extruded, the plastic quickly solidifies and fuses with the underlying adjacent layer. FDM 3D printers are
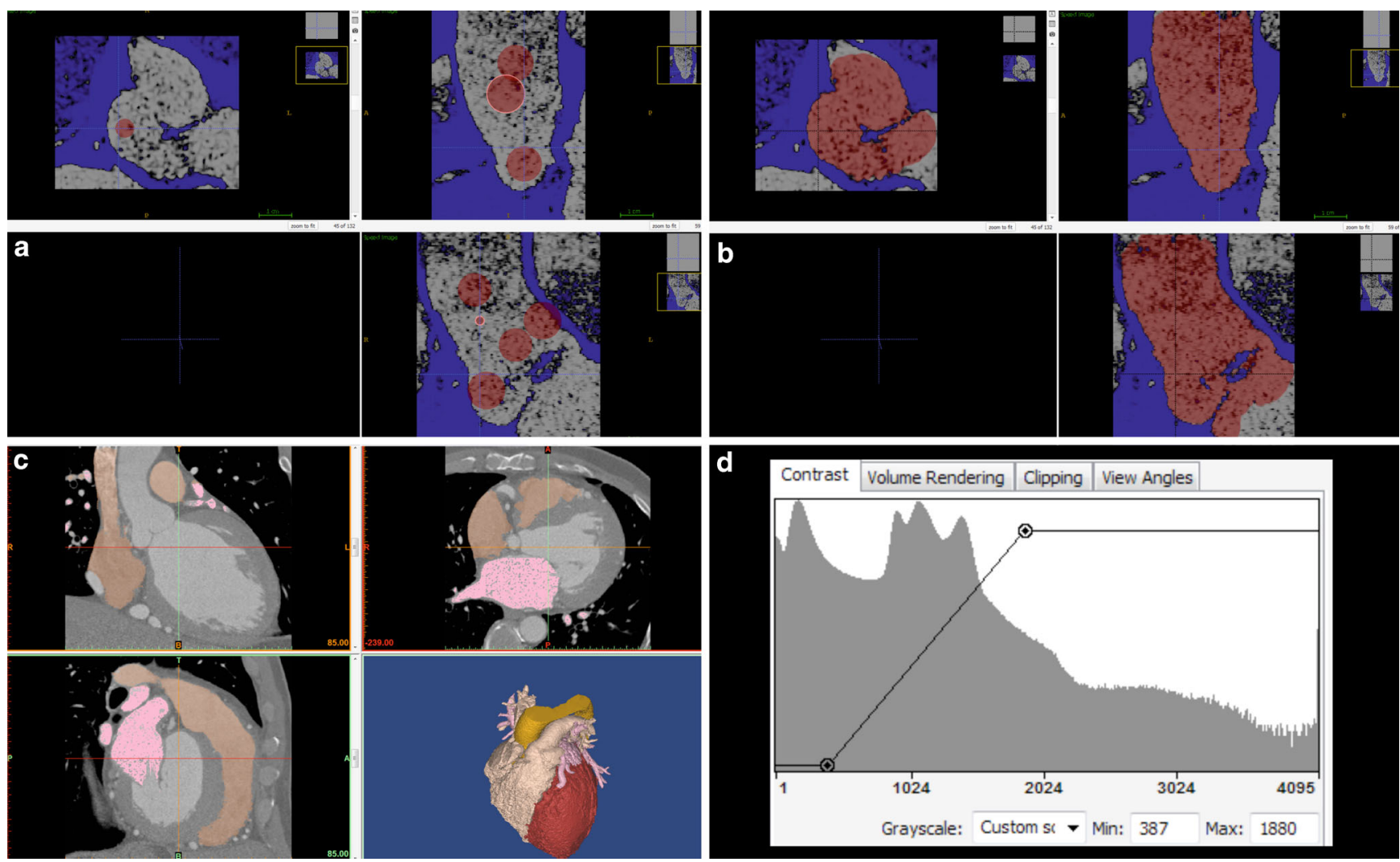

Fig. 2 Image segmentation process. a,b Screenshot from ITK-SNAP-Software (http://www.itksnap.org) Region growing as part of segmentation. a Example of segmentation via region growth (aorta). Select the region of interest for semi-automatic active contour segmentation and laying down the red dots to define where the region of interest is. b Activating the algorithm causes the dots to expand into the region of interest. $\mathbf{c}$ Screenshot from Mimics-Software as an example of thresholding and manual editing. $\mathbf{d}$ The histogram window on the bottom right-hand corner is the graph where thresholding is usually set 
Table 1 Summary of 3D printer technologies

\begin{tabular}{|c|c|c|c|}
\hline 3D printer technology & Type of materials used & Strengths & Limitations \\
\hline $\begin{array}{l}\text { Fused Deposition Modelling } \\
\text { (FDM) }\end{array}$ & Thermoplastics & $\begin{array}{l}\text { Low cost, easy to operate, wide } \\
\text { variety of usable thermoplastic } \\
\text { materials for printing }\end{array}$ & $\begin{array}{l}\text { Relatively long print times, } \\
\text { print resolution low compared } \\
\text { with other types of printers } \\
(0.1-1.2 \mathrm{~mm})\end{array}$ \\
\hline Stereolithography (SLA) & Photosensitive resins & $\begin{array}{l}\text { Can be low cost, high resolution } \\
(0.025-0.1 \mathrm{~mm}) \text {, excellent print } \\
\text { surface quality }\end{array}$ & $\begin{array}{l}\text { Relatively long print times, ex- } \\
\text { tensive post-processing required, } \\
\text { higher end expensive industrial } \\
\text { grade printers }\end{array}$ \\
\hline $\begin{array}{l}\text { Continuous Liquid Interface } \\
\text { Production (CLIP) }\end{array}$ & Photosensitive resins & $\begin{array}{l}\text { Extremely fast print speeds, high } \\
\text { resolution prints }\end{array}$ & $\begin{array}{l}\text { Printers cannot be purchased, bu } \\
\text { may be leased on a year-to-year } \\
\text { basis }\end{array}$ \\
\hline PolyJet & Photosensitive resins & $\begin{array}{l}\text { Extremely high resolution ( } 16 \text { mi- } \\
\text { crons), multi-durometer printing, } \\
\text { multi-coloured printing, large build } \\
\text { volume }\end{array}$ & $\begin{array}{l}\text { Expensive to purchase and oper- } \\
\text { ate, printed objects are relatively } \\
\text { brittle }\end{array}$ \\
\hline Selective Laser Sintering (SLS) & $\begin{array}{l}\text { Chamber of powdered mate- } \\
\text { rial including nylons, glass, } \\
\text { ceramics and metal }\end{array}$ & $\begin{array}{l}\text { Very large build volumes can pro- } \\
\text { duce mechanically functional prints } \\
\text { out of ceramics and metals, excel- } \\
\text { lent surface quality and precision }\end{array}$ & $\begin{array}{l}\text { Expensive to purchase and op- } \\
\text { erate, difficult to operate and } \\
\text { calibrate }\end{array}$ \\
\hline
\end{tabular}

capable of producing layers between 0.1 and $1.2 \mathrm{~mm}$ thick. A growing variety of stiff and elastomeric thermoplastics have recently become available. Desktop FDM 3D printers typically cost a few thousand US dollars and the thermoplastic filaments range from 20 to 100 US dollars per $\mathrm{kg}$, making fabrication costs relatively affordable.

SLA printers utilise a photosensitive resin and ultraviolet light. The ultraviolet light traces the geometry of an object into a resin bath causing photo-polymerisation of the resin into a solid [13]. Desktop SLA 3D printers are available and priced similarly to FDM systems with a slightly higher production cost. SLA printers provide extremely high resolution ranging from 0.025 to $0.1 \mathrm{~mm}$ with excellent surface finish after considerable post-processing [13]. The main drawbacks of desktop SLA printers are the relatively small build volumes and long build times required to cure the photosensitive resins into 3D models. However, recent advances in printers utilising similar technology, such as Continuous Liquid Interface Production (CLIP), has dramatically reduced print times [14].

PolyJet printers utilise a photo curable resin sprayed in a very fine layer and then cured into a solid via ultraviolet light $[13,14]$. PolyJet printers allow extremely high resolution of 16 microns and the ability to produce regions of variable durometer within a single 3D printed object. Furthermore, objects can be produced with a wide spectrum of colour within the same print. These printers are in the order of hundreds of thousands of US dollars and have a relatively high production cost.

\section{Applications of 3D printing}

Due to its ability to illustrate complex anatomy of cardiovascular structures and cavities, 3D printing is rapidly gaining interest in interventional cardiology and cardiovascular surgery [5]. Over the past 5 years there has been a remarkable increase in published studies and case reports for applications of 3D printing in structural and congenital heart disease interventions gap (Table 2 and 3). The applications of $3 \mathrm{D}$ printing vary from anatomical education and training, to preprocedural planning, simulation and device testing [15].

\section{Education and training}

Conceptual 3D understanding of complex cardiac structures remains a main challenge for cardiologists and radiologists and it is traditionally taught using 2D images or pathological specimens. 3D printing allows the development of accurate life-like educational tools (Fig. 3) to illustrate complex cardiovascular anatomy and pathology. In terms of qualitative assessment of knowledge reporting, knowledge acquisition and structural conceptualisation, 3D printed models have been shown to improve physicians' understanding of congenital heart disease compared with regular imaging modalities [15]. Patient-specific 3D printing models have the potential to enhance engagement with patients and improve communication between the cardiologist and the patient's family. Better understanding may also impact a patient's psychological adaptation following treatment [4]. 
Fig. 3 3D printing models for educational purposes. a,b SLA transparent full heart model demonstrating normal anatomy. c,d FDM models illustrating standard transthoracic echocardiographic 2D views (c apical four chamber view; $\mathbf{d}$ parasternal long axis)
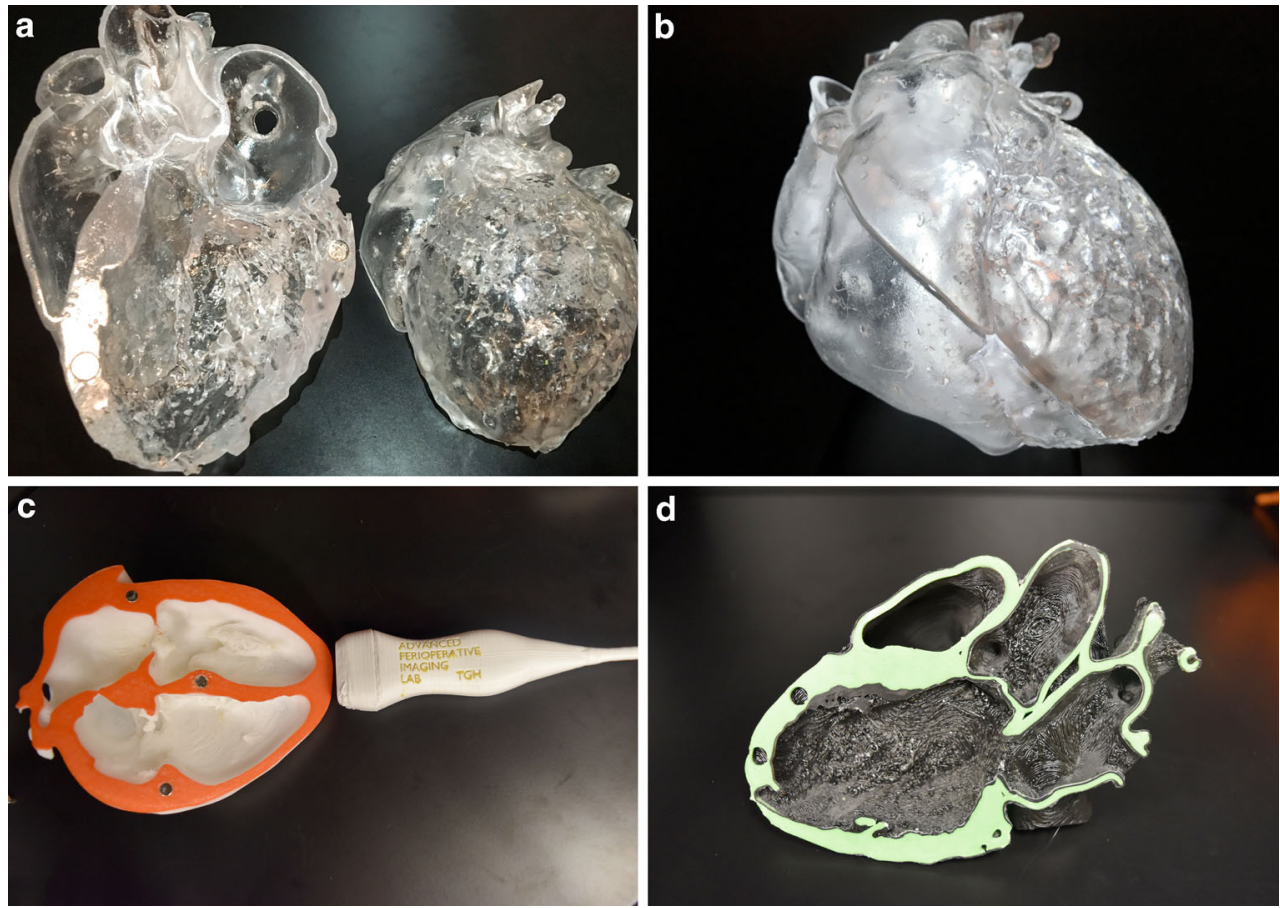

\section{Structural and valvular heart disease interventions}

In structural heart disease interventions, the vast majority of $3 \mathrm{D}$ printed models have been used to assist planning and simulating complex interventions (Table 2), especially when common $2 \mathrm{D}$ or $3 \mathrm{D}$ imaging modalities raise uncertainties in terms of access relationships, or location of defects or certain structures.

Chaowu et al. reported a successful in vitro trial occlusion of an atrial septal defect (ASD) with rim deficiency on the basis of a personalised 3D printed heart model. It has shown to be a feasible method to identify the appropriate candidates, especially for large ASDs with rim deficiency, and thus decreases related complications [16]. 3D printed models have shown to be beneficial in preprocedural planning and device testing of other transcatheter interventions such as left atrial appendages occlusions [17] and interventions on the ascending aorta [18].
Case example (Fig. 4)

Referring to other reports, at our centre we have successfully closed a post-inferior myocardial infarction ventricular septal defect (VSD) with a post-infarct VSD occluder device based on a CT-derived 3D printed model. A 63year-old woman with a subacute post-infarct VSD and related pulmonary hypertension and was considered for transcatheter closure. The CT revealed a large defect in the basal to mid inferior septum which measured approximately $31 \times 32 \times 23 \mathrm{~mm}$ en face. We questioned the precision of these measurements and produced a polylactic acid (PLA) FDM 3D printed model of the patient's septum and inferior VSD. On preprocedural angiography and transoesophageal echocardiography (TEE) the maximal diameter of the VSD was between 11 and $13 \mathrm{~mm}$ and was consistent with the measurements and morphology of the 3D printed model. We were able to successfully deliver an $18 \mathrm{~mm}$ Amplatzer
Fig. 4 FDM/PLA - 3D printing model of an inferior post-myocardial infarction VSD with aneurysm. Amplatzer device crossing the VSD from the venous, right ventricular side. a right ventricular view. b left ventricular view
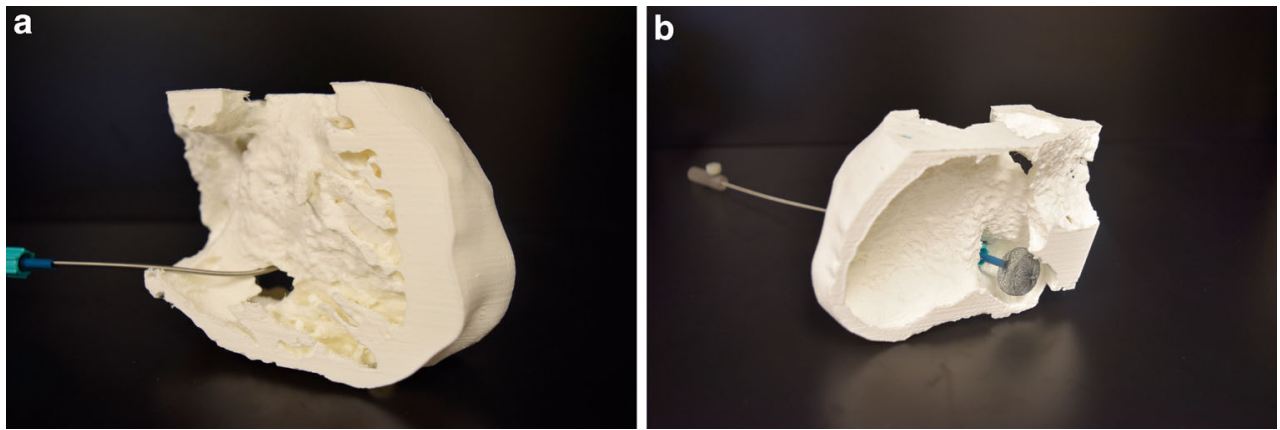
Table 2 Overview on literature on 3D printing applications for transcatheter interventions in structural and valvular heart disease

\begin{tabular}{|c|c|}
\hline Topic & Application of 3D printing models \\
\hline \multicolumn{2}{|c|}{ Acquired structural heart disease } \\
\hline Coronary interventions & $\begin{array}{l}\text { Coronary 3D models for percutaneous inter- } \\
\text { vention (PCI) optimisation strategies }[33,34]\end{array}$ \\
\hline Left atrial appendage (LAA) & $\begin{array}{l}\text { 3D printing models for planning/simulating } \\
\text { LAA occlusion procedures }[35,36]\end{array}$ \\
\hline Great vessels & $\begin{array}{l}\text { Interventions of ascending aorta: } \\
\text { - Custom-made devices for coil embolisa- } \\
\text { tion of an anastomotic leak after aortic arch } \\
\text { replacement [18] } \\
\text { - Occlusion of an ascending aortic pseudo } \\
\text { aneurysm [37] }\end{array}$ \\
\hline & $\begin{array}{l}\text { Preprocedural planning/simulating trans- } \\
\text { catheter caval valve implantation [38] }\end{array}$ \\
\hline
\end{tabular}

Valvular heart disease

Aortic valve

Tricuspid valve

Planning of percutaneous tricuspid interventions [43] catheter aortic valve implantations (TAVI) [21, 39]

- Calcium distribution patterns of the aortic valve as a risk factor for the need of permanent pacemaker implantation [40]

- 3D printing of aortic roots to design tailored transcatheter stented aortic valves [41, 42]

Replicating patient-specific severe aortic valve stenosis with functional 3D modelling [22]

Mitral valve

Preprocedural planning/simulating transcatheter mitral valve interventions $[19,23]$

Pulmonary valve

See congenital heart disease (Table 2)

Benefit

- In vitro simulation of PCI in complex coronary anatomy

- In vitro stent placement and hydrofluid testing of haemodynamics and stent positioning

- Virtual modelling of fractional flow reserve (FFR) and hyperaemic stenosis resistance index

- LAA 3D models effectively guide device selection and placement of the LAA occlusion device

- Optimising transseptal puncture in LAA occlusion

- Choosing the treatment option, planning and simulating the occlusion of the pseudoaneurysm

- 3D models are used to build the custom-made occluder device

- 3D printing of the right atrial-inferior caval vein (RA-IVC) topography aids in transcatheter valve selection

- Patient-specific 3D models to assess the physical interplay of the aortic root and implanted valves.

- 3D models may complement traditional techniques used for predicting which patients are more likely to develop paravalvular aortic regurgitation

- 3D printed tissue-mimicking aortic root may enable predictions of post-TAVI root strain and distribution and aortic flow pattern

- Using fused dual-material 3D printing and an in vitro pulsatile flow loop demonstrates that patient-specific models can replicate both the anatomic and functional properties of severe degenerative aortic valve stenosis

- Preprocedural evaluation of catheter-based repair devices within specific patient 3D printed valve geometry

- Integration of CT and 3D print could assist in predicting left ventricular outflow tract obstruction

- 3D models of normal and pathological mitral valve annuli before and after repair procedures

- 3D printing is helpful clinical tool for planning and training operators in the early stage of this innovative intervention

- Measuring valvular diameters on 3D models is feasible and compared with measurements of 2D imaging and models, indicating accuracy of $<1 \mathrm{~mm}$
(St. Jude Medical Inc., USA) post-infarct VSD device (Fig. 4).

\section{Valvular interventions}

Cardiac valves are fast moving structures that are best imaged using 3D echocardiography. One exception is severely calcified, relatively immobile aortic valves and roots that have been successfully reconstructed using CT data. Echocardiography has been used to print accurate rigid 3D models of the mitral valve and ring [19]. A flex- ible mitral valve has also been created on a 3D printed mould and tested in a pulse replicator [20].

Combined-material 3D printed aortic valve and root has been reported to mimic calcified regions and become an accurate tool for preprocedural testing of transcatheter aortic valve implantation and predict paravalvular regurgitation [21]. 3D printed models also seem to replicate the anatomic and functional properties of severe degenerative aortic valve stenosis in in-vitro flow systems [22]. 3D printing of cell scaffoldings is in the very early testing phase for the aor- 
Fig. 5 Surgical repair of a supra-cardiac total anomalous pulmonary venous connection with redirection of the pulmonary veins to a confluence prior to connection to the left atrium. Haemodynamically relevant stenosis between confluence and the left atrium. a,b FDM 3D printed model showing anatomy of the pulmonary venous (PV) confluence and the left atrium (LA), anterior (a) and posterior (b) view. c,d Periprocedural angiography. c Draining PV confluence and stenosis, (d) relief of stenosis post stenting. e,f Periprocedural TEE. 2D and colour flow Doppler showing relevant stenosis between PV confluence and LA with relevant proximal isovelocity surface area (PISA) before dilatation and stenting (e) and no relevant stenosis post stenting (f)
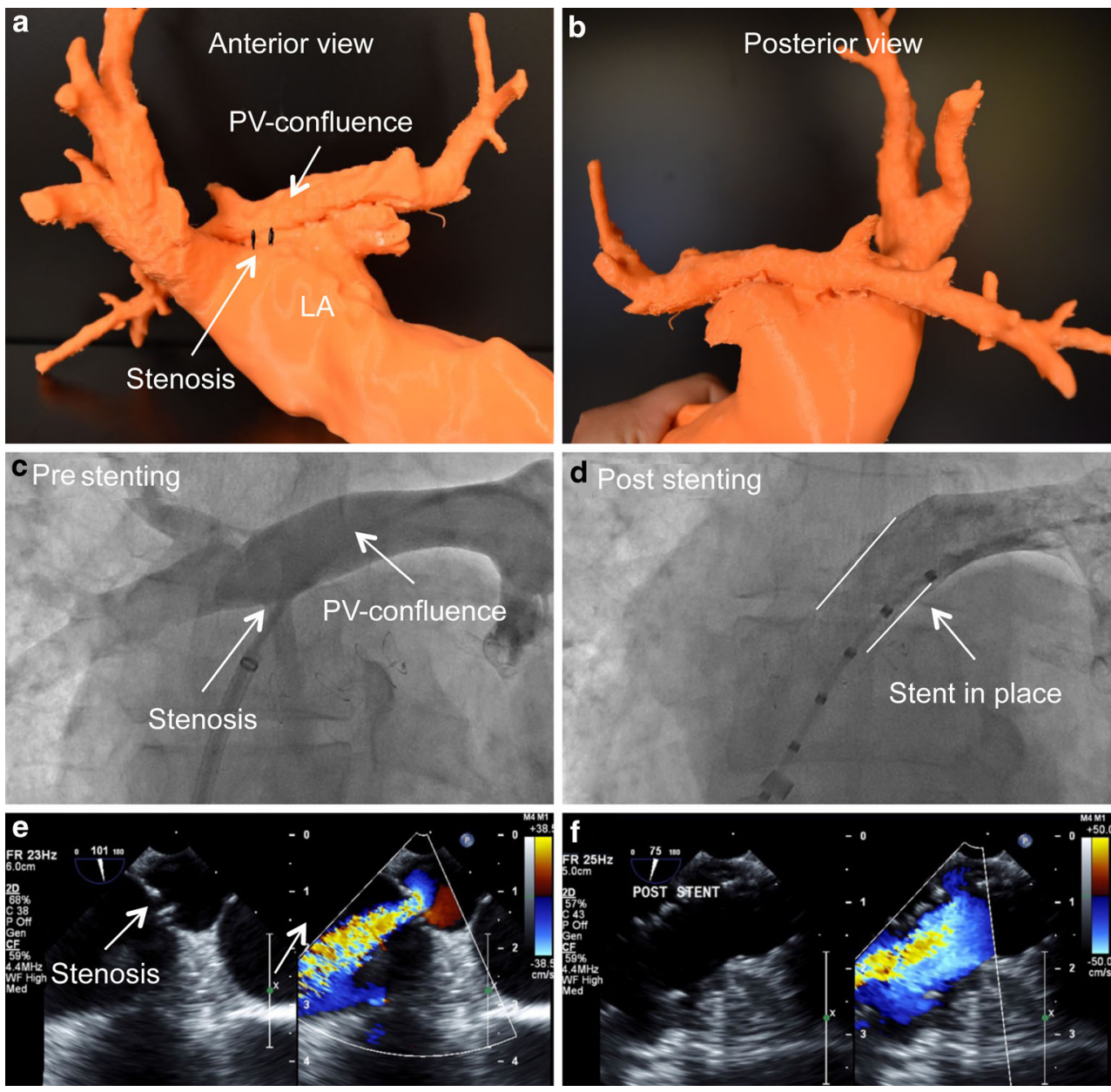

tic root, and has the potential for personalised implantable device fabrication and valve tissue engineering [18, 23].

\section{Congenital heart disease interventions}

Despite current classifications and treatment guidelines [24, 25] for adults with congenital heart disease, most of the management options are customised to individual patient anatomic variations, more so than with acquired disease. This makes patient-specific 3D printed models an ideal tool in this subset of patients for the planning of catheter-based (Table 3) and surgical interventions [4, 5, 8, 15].

Poterucha et al. reported the use of 3D right ventricular outflow tract printing and 3D rotational angiography to guide pulmonary valve stenting and valve implantation [26]. Hybrid 3D printed heart models of congenitally corrected transposition of the great arteries (TGA) [8] and dextroTGA after a Mustard operation [27] have been produced for illustrating the volume and morphologies of the chambers and proximal vessels. For those patients, 3D models could provide important insights into the changes in size and shape of the different chambers and the anatomy of vessels entering and exiting the baffles to the related ventricle.

In the future 3D printed vascular grafts for patients with congenital heart disease could be biodegradable, mechanically compatible with vascular tissues, and support neotissue formation and growth [28].

\section{Case example (Fig. 5)}

A 64-year-old patient with a history of surgical repair of supra-cardiac total anomalous pulmonary venous return with redirection of the pulmonary veins to a confluence prior to connection to the left atrium was admitted due to progressive dyspnoea on exertion. MRI and TEE showed a haemodynamically relevant stenosis between this confluence and the left atrium which led to pulmonary hypertension. Consensus was to proceed with balloon dilatation and stenting of the narrowed connection to the left atrium.

As seen in Fig. 5, the patient specific 3D printed model was especially helpful in periprocedural planning. It helped to visualise the spatial orientation of the pulmonary venous confluence, the orifice and its relation to the left 
Table 3 Overview on literature on 3D printing applications for education and transcatheter interventions in congenital heart disease

\begin{tabular}{|c|c|c|}
\hline Topic & Application of 3D printing models & Benefit \\
\hline \multicolumn{3}{|l|}{ Congenital heart disease } \\
\hline \multirow[t]{3}{*}{ Complex congenital anatomy } & $\begin{array}{l}\text { Physician education and understanding of } \\
\text { complex anatomy }[15,44]\end{array}$ & $\begin{array}{l}\text { - Effective educational tool for physicians to improve } \\
\text { understanding of congenital cardiac anatomy } \\
\text { - Subjective improvement of understanding of congeni- } \\
\text { tal heart disease with 3D printing models compared to } \\
\text { regular 2D/3D imaging modalities (e. g. CT/MRI) }\end{array}$ \\
\hline & $\begin{array}{l}\text { Patient-specific 3D printing models for } \\
\text { patient education and communication [4] }\end{array}$ & $\begin{array}{l}\text { - Patient-specific models can enhance engagement with } \\
\text { parents and improve communication between cardiolo- } \\
\text { gists and patient/parents }\end{array}$ \\
\hline & $\begin{array}{l}\text { Deriving 3D printing models from echocar- } \\
\text { diography and combined imaging modali- } \\
\text { ties }[8,26,45]\end{array}$ & $\begin{array}{l}\text { - Feasibility of deriving 3D printing from ultrasound pro- } \\
\text { vides an additional cost-effective and patient-centred } \\
\text { option } \\
\text { - Integration of the strengths of two or more imaging } \\
\text { modalities into 3D printing is feasible and has the poten- } \\
\text { tial to enhance visualisation of cardiac pathomorphology }\end{array}$ \\
\hline Atrial septal defect (ASD) & $\begin{array}{l}\text { Preprocedural planning/simulating of trans- } \\
\text { catheter ASD closure: } \\
\text { - secundum ASD with rim deficiency [16] } \\
\text { - inferior vena cava type ASD with patent } \\
\text { ductus arteriosus occlusion device [46] }\end{array}$ & $\begin{array}{l}\text {-3D printing models allowed to overcome the 3D visu- } \\
\text { alisation of the ASD and guides device selection and } \\
\text { placement }\end{array}$ \\
\hline Ventricular septal defect (VSD) & $\begin{array}{l}\text { - Preprocedural planning of transcatheter } \\
\text { VSD closure for postinfarct or complex } \\
\text { muscular VSDs }[47,48]\end{array}$ & $\begin{array}{l}\text { - Utilising 3D printing model to visualise location and } \\
\text { size of VSD as well as trabeculations, papillary muscle } \\
\text { bundles to guide size and type of septal occluder }\end{array}$ \\
\hline Aortic coarctation & $\begin{array}{l}\text { Planning/simulating endovascular stenting } \\
\text { in transverse aortic arch hypoplasia [49] }\end{array}$ & $\begin{array}{l}\text { - 3D printing models accurately replicate patients' } \\
\text { anatomy and are helpful in planning endovascular stent- } \\
\text { ing in transverse arch hypoplasia }\end{array}$ \\
\hline $\begin{array}{l}\text { Transposition of the great arter- } \\
\text { ies (TGA) }\end{array}$ & $\begin{array}{l}\text { Hybrid 3D printing with congenitally cor- } \\
\text { rected transposition of the great arteries } \\
\text { (ccTGA) [8] } \\
\text { Patient-specific 3D models of the cardiac } \\
\text { chambers of a patient with D-TGA after the } \\
\text { Mustard operation [27] }\end{array}$ & $\begin{array}{l}\text { - 3D models give important insights into the changes in } \\
\text { size and shape of the different chambers and the patterns } \\
\text { of blood flow from the pulmonary and systemic veins to } \\
\text { the "appropriate" ventricle. } \\
\text { - Helpful in understanding and optimising the overall } \\
\text { haemodynamic function after the Mustard operation }\end{array}$ \\
\hline
\end{tabular}

atrium. After a transseptal puncture we successfully performed a balloon dilatation and a subsequent stenting of the narrowed confluence orifice (Genesis 3910B stent mounted on a $14 \mathrm{~mm}$, Z-Med II balloon) into the confluence.

\section{Establishing an in-hospital 3D printing laboratory}

Establishing a 3D printing laboratory requires planning in three main categories: hardware, software and personnel. The necessary hardware includes: computer workstations, secured data storage, connectivity to the hospital imaging network and 3D printers. As previously described, the price of printers varies from a few thousands for desktop FDMs to a million US dollars for an industrial SLA. The following factors help guiding the choice of 3D printer: 3D print volume, turnaround time, type and need to merge of multiple materials. The costs of maintenance, printing materials and development cycle of new technologies have to be considered in this planning stage. Low cost desktop printers have significantly improved their performance over the past few years and allow affordable prototyping, making them ideal throughout the learning phase of segmentation and printing. Outsourcing single, more complex, prints should be considered as well as acquiring printers in stages as the applications and workload demand.

A range of free, open-source software packages can be part of the processes of segmentation, model editing, de novo modelling and slicing for $3 \mathrm{D}$ printing. These include software which runs effectively on modern laptops and desktops in Windows and Mac OS environments. 3D Slicer [11] and ITK-SNAP [10, 29] are typically used for segmentation and Meshmixer (Autodesk Inc., USA) for model editing. Slicing for 3D printing can be performed with a variety of software such as Slic3r (GNU Affero General Public License, version 3) or PreForm software (Formlabs, USA) depending on the printer being used. De novo modelling and computer-aided design work can be performed with tools such as Blender [30] and FreeCAD [31]. Mimics segmentation software (Materialise, Belgium) allows semi-automated segmentation and 3D modelling on echocardiographic datasets. Mimics is proprietary and has a yearly licensing fee. 
Lab staffing depends upon the workload, the complexity and type of the models generated and the imaging modality used. As an example, CT-based 3D model of bony structures are far less time consuming than echo-based models. A biomedical industrial designer who is trained in performing 3D segmentations would be the ideal key player in the lab but will need to work in direct contact with an imaging or clinical medical specialist to guarantee the accuracy of the end products.

\section{Limitations and challenges}

Several limitations exist with current 3D printing technologies. First, 3D printed objects are limited in replicating the dynamic properties of the organs which they seek to replicate [32]. While PolyJet printing technology can produce objects with regions of varying properties, full replication of the mechanical properties of cardiac tissue and its complex, anisotropic structure has yet to be achieved. Secondly, current image segmentation software requires a great deal of non-automated human input to produce a 3D model capable of being printed. This has a major impact on resource utilisation, as it requires dedicated trained personnel who are difficult to justify at the moment for current experimental clinical application. Additionally, this process is time consuming and is prone to human operator error and bias. This raises the issue of consistency in model accuracy. Similarly, the time required to print even a small isolated portion of the heart is in the order of at least one hour with most available printers which limits the viability of 3D printing for urgent cases. Therefore cost-effectiveness, model accuracy and clinical impact require more research and scientific data.

Lastly, visualising complex intracardiac lesions or guiding devices while simulating procedures sometimes requires the printed models to be pellucid or have static cut planes depending on the viewing angle. These can lead to time consuming reproduction of different 3D printing models for the same lesion and thus getting away from its original purpose of a comprehensive model.

Emerging virtual reality 3D imaging technologies such as Echopixel (EchoPixel, Inc., USA) or Real View Medical Holography (RealView Imaging Ltd., Israel) could be complementary tools to address those limitations. Whereas the segmentation process of the acquired images mainly remains the same for $3 \mathrm{D}$ printing and $3 \mathrm{D}$ virtual imaging, the STL files of the virtual 3D models can easily be uploaded into these virtual reality $3 \mathrm{D}$ tools to optimise illustration and the viewing angle of lesions by adding cutting planes. However, the tangible aspect and mimicking of tissue behaviour can only be assessed with a physical model.

\section{Conclusion}

3D printing is a very powerful tool in structural and congenital heart disease interventions. It overcomes some of the limitations of conventional 2D/3D imaging methods by providing a tangible, physical 3D model of complex cardiovascular structures. 3D models have shown promising results in widespread applications from education to procedural planning and device testing. However, most of the current literature is based on feasibility studies and subjective qualitative comparisons with traditional imaging modalities. The role of $3 \mathrm{D}$ printing models in day-to-day clinical care as it pertains to morbidity and mortality is yet to be determined. More work is finally needed to automate and standardise the image segmentation process to decrease costs of personnel and allow reproducible findings. Lastly, evolving visualisation software solutions that can generate holographic 3D models, therefore acting as "virtual" 3D prints, are highly complementary to 3D printing especially because they allow dynamic rendering and cutting planes to optimise viewing angles.

Funding Dr Meier is supported by a grant from the Gottfried und Julia Bangerter-Rhyner-Stiftung. Dr Horlick is supported by the Peter Munk Chair in Structural Heart Disease Intervention. Dr Meineri is the director of The Lynn \& Arnold Irwin Advanced Perioperative Lab which is supported by a charitable donation by the Irwing Family through the Peter Munk Cardiac Foundation.

Conflict of interest L.M. Meier, M. Meineri, J. Qua Hiansen and E.M. Horlick declare that they have no competing interests.

Open Access This article is distributed under the terms of the Creative Commons Attribution 4.0 International License (http:// creativecommons.org/licenses/by/4.0/), which permits unrestricted use, distribution, and reproduction in any medium, provided you give appropriate credit to the original author(s) and the source, provide a link to the Creative Commons license, and indicate if changes were made.

\section{References}

1. Carroll JD, Webb JG. Structural Heart Disease Interventions. Philadelphia: Lippincott Williams \& Wilkins; 2012.

2. D’Urso PS, Barker TM, Earwaker WJ, et al. Stereolithographic biomodelling in cranio-maxillofacial surgery: a prospective trial. J Craniomaxillofac Surg. 1999;27:30-7.

3. Hananouchi T, Saito M, Koyama T, et al. Tailor-made surgical guide based on rapid prototyping technique for cup insertion in total hip arthroplasty. Int J Med Robot. 2009;5:164-9.

4. Biglino G, Capelli C, Wray J, et al. 3D-manufactured patientspecific models of congenital heart defects for communication in clinical practice: feasibility and acceptability. BMJ Open. 2015;5:e007165.

5. Schmauss D, Haeberle S, Hagl C, Sodian R. Three-dimensional printing in cardiac surgery and interventional cardiology: a singlecentre experience. Eur J Cardiothorac Surg. 2014;47:1044-52.

6. Kim MS, Hansgen AR, Wink O, Quaife RA, Carroll JD. Rapid prototyping: a new tool in understanding and treating structural heart disease. Circulation. 2008;117:2388-94. 
7. Byrne N, Velasco Forte M, Tandon A, Valverde I, Hussain T. A systematic review of image segmentation methodology, used in the additive manufacture of patient-specific 3D printed models of the cardiovascular system. JRSM Cardiovasc Dis. 2016;5: 2048004016645467.

8. Gosnell J, Pietila T, Samuel BP, Kurup HK, Haw MP, Vettukattil JJ. Integration of computed tomography and three-dimensional echocardiography for hybrid three-dimensional printing in congenital heart disease. J Digit Imaging. 2016;12:12.

9. Mitsouras D, Liacouras P, Imanzadeh A, et al. Medical 3D printing for the radiologist. Radiographics. 2015;35:1965-88.

10. ITK-SNAP. Available from: http://www.itksnap.org [Accessed 23th July 2016].

11. 3D Slicer. Available from: http://www.slicer.org [Accessed 23th July 2016].

12. Mathur M, Patil P, Bove A. The role of 3D printing in structural heart disease: all that glitters is not gold. JACC Cardiovasc Imaging. 2015;8:987-8.

13. Kim GB, Lee S, Kim H, et al. Three-dimensional printing: basic principles and applications in medicine and radiology. Korean $\mathrm{J}$ Radiol. 2016;17:182-97.

14. Ibrahim D, Broilo TL, Heitz C, et al. Dimensional error of selective laser sintering, three-dimensional printing and PolyJet models in the reproduction of mandibular anatomy. J Craniomaxillofac Surg. 2009;37:167-73

15. Costello JP, Olivieri LJ, Su L, et al. Incorporating three-dimensional printing into a simulation-based congenital heart disease and critical care training curriculum for resident physicians. Congenit. 2015;10:185-90.

16. Chaowu Y, Hua L, Xin S. Three-dimensional printing as an aid in transcatheter closure of secundum atrial septal defect with rim deficiency: in vitro trial occlusion based on a personalized heart model. Circulation. 2016;133:e608-e610.

17. Pellegrino PL, Fassini G, Di Biase M, Tondo C. Left atrial appendage closure guided by $3 \mathrm{D}$ printed cardiac reconstruction: emerging directions and future trends. J Cardiovasc Electrophysiol. 2016;27:768-71.

18. Sodian R, Schmauss D, Schmitz C, et al. 3-dimensional printing of models to create custom-made devices for coil embolization of an anastomotic leak after aortic arch replacement. Ann Thorac Surg. 2009;88:974-8.

19. Mahmood F, Owais K, Montealegre-Gallegos M, et al. Echocardiography derived three-dimensional printing of normal and abnormal mitral annuli. Ann Card Anaesth. 2014;17:279-83.

20. Mashari A, Knio Z, Jeganathan J, et al. Hemodynamic testing of patient-specific mitral valves using a pulse duplicator: a clinical application of three-dimensional printing. J Cardiothorac Vasc Anesth. 2016;30:1278-85.

21. Ripley B, Kelil T, Cheezum MK, et al. 3D printing based on cardiac $\mathrm{CT}$ assists anatomic visualization prior to transcatheter aortic valve replacement. J Cardiovasc Comput Tomogr. 2016;10:28-36.

22. Maragiannis D, Jackson MS, Igo SR, et al. Replicating patientspecific severe aortic valve stenosis with functional 3D modeling. Circ Cardiovasc Imaging. 2015;8:e003626.

23. Owais K, Pal A, Matyal R, et al. Three-dimensional printing of the mitral annulus using echocardiographic data: science fiction or in the operating room next door? J Cardiothorac Vasc Anesth. 2014;28:1393-6.

24. Baumgartner H, Bonhoeffer P, De Groot NM, et al. ESC Guidelines for the management of grown-up congenital heart disease (new version 2010). Eur Heart J. 2010;31:2915. doi:10.1093/eurheartj/ ehq249.

25. Warnes CA, Williams RG, Bashore TM, et al. ACC/AHA 2008 Guidelines for the Management of Adults With Congenital Heart Disease: A Report of the American College of Cardiology/ American Heart Association Task Force on Practice Guidelines
(Writing Committee to Develop Guidelines on the Management of Adults With Congenital Heart Disease) Developed in Collaboration With the American Society of Echocardiography, Heart Rhythm Society, International Society for Adult Congenital Heart Disease, Society for Cardiovascular Angiography and Interventions, and Society of Thoracic Surgeons. J Am Coll Cardiol. 2008;52:e143-e263.

26. Poterucha JT, Foley TA, Taggart NW. Percutaneous pulmonary valve implantation in a native outflow tract: 3-dimensional DynaCT rotational angiographic reconstruction and 3-dimensional printed model. JACC Cardiovasc Interv. 2014;7:e151-2.

27. Chapron J, Hosny H, Torii R, Sedky Y, Donya M, Yacoub MH. Lessons from patient-specific 3D models of the cardiac chambers after the Mustard operation. Glob Cardiol Sci Pract. 2013;2013: 409-15.

28. Melchiorri AJ, Hibino N, Best CA, et al. 3D-printed biodegradable polymeric vascular grafts. Adv Healthc Mater. 2016;5:319-25.

29. Yushkevich PA, Piven J, Hazlett HC, et al. User-guided 3D active contour segmentation of anatomical structures: significantly improved efficiency and reliability. Neuroimage. 2006;31:1116-28.

30. blender. Available from: https://www.blender.org [Accessed 23th July 2016].

31. FreeCAD. Available from: http://www.freecadweb.org [Accessed 23th July 2016].

32. Shi D, Liu K, Zhang X, Liao H, Chen X. Applications of threedimensional printing technology in the cardiovascular field. Intern Emerg Med. 2015;10:769-80.

33. Wang H, Liu J, Zheng X, et al. Three-dimensional virtual surgery models for percutaneous coronary intervention (PCI) optimization strategies. Sci Rep. 2015;5:10945.

34. Saito N, Tatsushima S, Tazaki J, et al. Patient-specific three-dimensional aortocoronary model for percutaneous coronary intervention of a totally occluded anomalous right coronary artery. J Invasive Cardiol. 2015;27:E139-E142.

35. Otton JM, Spina R, Sulas R, et al. Left atrial appendage closure guided by personalized 3D-printed cardiac reconstruction. JACC Cardiovasc Interv. 2015;8:1004-6.

36. Fan Y, Kwok KW, Zhang Y, Cheung GS, Chan AK, Lee AP. Three-dimensional printing for planning occlusion procedure for a double-lobed left atrial appendage. Circ Cardiovasc Interv. 2016;9(3):e003561.

37. Li F, Shan Y, Zhang Y, Niu G. Occlusion of an ascending aortic pseudoaneurysm with intraoperative echocardiography and a printed model. J Thorac Cardiovasc Surg. 2016;152:282-4.

38. O'Neill B, Wang DD, Pantelic M, et al. Transcatheter caval valve implantation using multimodality imaging: roles of TEE, CT, and 3D printing. JACC Cardiovasc Imaging. 2015;8:221-5.

39. Gallo M, D’Onofrio A, Tarantini G, Nocerino E, Remondino F, Gerosa G. 3D-printing model for complex aortic transcatheter valve treatment. Int J Cardiol. 2016;210:139-40.

40. Fujita B, Kutting M, Seiffert M, et al. Calcium distribution patterns of the aortic valve as a risk factor for the need of permanent pacemaker implantation after transcatheter aortic valve implantation. Eur Heart J Cardiovasc Imaging. 2016;12:12.

41. Kalejs M, von Segesser LK. Rapid prototyping of compliant human aortic roots for assessment of valved stents. Interact Cardiovasc Thorac Surg. 2009;8:182-6.

42. Qian Z, Wang K, Chang YH, et al. 3-D printing of biological tissue-mimicking aortic root using a novel meta-material technique: Potential clinical applications. J Am Coll Cardiol. 2016;67(13S):7.

43. Taramasso M, Phalla O, Spagnolo P, et al. 3D heart models for planning of percutaneous tricuspid interventions. J Am Coll Cardiol. 2015;(1):B53. doi:10.1016/j.jacc.2015.08.161.

44. Shiraishi I, Kajiyama Y, Yamagishi M, Hamaoka K. Stereolithographic biomodeling of congenital heart disease by multislice computed tomography imaging. Circulation. 2006;113:e733-e734. 
45. Moore T, Madriago EJ, Renteria ES, et al. Co-registration of 3D echo and MR data to create physical models of congenital heart malformations. J Cardiovasc Magn Reson. 2015;17:P198. doi:10. 1186/1532-429X-17-S1-P198.

46. Yang F, Zheng H, Lyu J, et al. A case of transcatheter closure of inferior vena cava type atrial septal defect with patent ductus arteriosus occlusion device guided by 3D printing technology. [Chinese. Zhonghua Xin Xue Guan Bing Za Zhi. 2015;43:631-3.

47. Lazkani M, Bashir F, Brady K, Pophal S, Morris M, Pershad A. Postinfarct VSD management using 3D computer printing assisted percutaneous closure. Indian Heart J. 2015;67:581-5.
48. Bhatla P, Chakravarti S, Yoo SJ, Thabit O, McElhinney D, Ludomirsky A. Candidacy for device closure of complex muscular ventricular septal defects: Novel application of rapid prototyping and virtual $3 \mathrm{~d}$ models derived fcardiac CT and MRI. J Am Coll Cardiol. 2015;65(10_S):A573. doi:10.1016/S0735-1097(15)60573-3.

49. Valverde I, Gomez G, Coserria JF, et al. 3D printed models for planning endovascular stenting in transverse aortic arch hypoplasia. Catheter Cardiovasc Interv. 2015;85:1006-12. 